Check for updates

Cite this: Chem. Sci., 2019, 10, 2199

๑ All publication charges for this article have been paid for by the Royal Society of Chemistry

Received 30th September 2018 Accepted 14th December 2018

DOI: $10.1039 / c 8 s c 04344 b$

rsc.li/chemical-science

\section{Cathodized copper porphyrin metal-organic framework nanosheets for selective formate and acetate production from $\mathrm{CO}_{2}$ electroreduction $\uparrow$}

\author{
Jian-Xiang Wu, Shu-Zhen Hou, Xiang-Da Zhang, Ming Xu, Hua-Fei Yang, \\ Pei-Sheng Cao and Zhi-Yuan Gu (D)*
}

\begin{abstract}
An efficient and selective $\mathrm{Cu}$ catalyst for $\mathrm{CO}_{2}$ electroreduction is highly desirable since current catalysts suffer from poor selectivity towards a series of products, such as alkenes, alcohols, and carboxylic acids. Here, we used copper(II) paddle wheel cluster-based porphyrinic metal-organic framework (MOF) nanosheets for electrocatalytic $\mathrm{CO}_{2}$ reduction and compared them with $\mathrm{CuO}, \mathrm{Cu}_{2} \mathrm{O}, \mathrm{Cu}$, a porphyrin-Cu(॥) complex and a $\mathrm{CuO} /$ complex composite. Among them, the cathodized $\mathrm{Cu}-\mathrm{MOF}$ nanosheets exhibit significant activity for formate production with a faradaic efficiency (FE) of $68.4 \%$ at a potential of $-1.55 \mathrm{~V}$ versus $\mathrm{Ag} / \mathrm{Ag}^{+}$. Moreover, the $\mathrm{C}-\mathrm{C}$ coupling product acetate is generated from the same catalyst together with formate at a wide voltage range of $-1.40 \mathrm{~V}$ to $-1.65 \mathrm{~V}$ with the total liquid product $\mathrm{FE}$ from $38.8 \%$ to $85.2 \%$. High selectivity and activity are closely related to the cathodized restructuring of Cu-MOF nanosheets. With the combination of X-ray diffraction, $\mathrm{X}$-ray photoelectron spectroscopy, high resolution transmission electron microscopy and Fourier transform infrared spectroscopy, we find that $\mathrm{Cu}(\|)$ carboxylate nodes possibly change to $\mathrm{CuO}, \mathrm{Cu}_{2} \mathrm{O}$ and $\mathrm{Cu}_{4} \mathrm{O}_{3}$, which significantly catalyze $\mathrm{CO}_{2}$ to formate and acetate with synergistic enhancement from the porphyrin- $\mathrm{Cu}(I)$ complex. This intriguing phenomenon provides a new opportunity for the rational design of high-performance Cu catalysts from pre-designed MOFs.
\end{abstract}

\section{Introduction}

The reduction of $\mathrm{CO}_{2}$ to useful chemicals holds great promise for reducing humanity's enormous carbon footprint. ${ }^{1-5}$ Electrochemical conversion of $\mathrm{CO}_{2}$ using electricity generated from renewable energy sources could provide a viable solution to the production of carbon-neutral fuels and chemicals. ${ }^{6-8}$ Current products from the $\mathrm{CO}_{2}$ reduction reaction $\left(\mathrm{CO}_{2} \mathrm{RR}\right)$ include carbon monoxide, alkenes, acids, and alcohols. ${ }^{9}$ Although many research studies focus on the production of potential fuels, such as $\mathrm{C}_{2} \mathrm{H}_{4}$, $\mathrm{CH}_{3} \mathrm{OH}$, and $\mathrm{C}_{2} \mathrm{H}_{5} \mathrm{OH},{ }^{10-12}$ a recent gross-margin model counterintuitively revealed that $\mathrm{HCOOH}$ and $\mathrm{CO}$ are the most economically viable products. ${ }^{13}$ Compared with gaseous $\mathrm{CO},{ }^{14-20}$ the liquid products $\mathrm{HCOOH}$ and $\mathrm{CH}_{3} \mathrm{COOH}$ are easy to collect and store. ${ }^{21}$ However, the formate and acetate production from the $\mathrm{CO}_{2} \mathrm{RR}$ still remains a scientific challenge. ${ }^{22}$ Major Sn-based catalysts usually suffer from limited reaction selectivity and a narrow range of active voltage ${ }^{23-25}$ although a recent Bi-based catalyst has shown

Jiangsu Key Laboratory of Biofunctional Materials, Jiangsu Collaborative Innovation Center of Biomedical Functional Materials, Jiangsu Key Laboratory of New Power Batteries, School of Chemistry and Materials Science, Nanjing Normal University, Nanjing, 210023, P. R. China. E-mail: guzhiyuan@njnu.edu.cn; Fax: +86-2585891952; Tel: +86-25-85891952

$\dagger$ Electronic supplementary information (ESI) available: Synthetic experimental details and additional figures (XRD and SEM data). See DOI: 10.1039/c8sc04344b high potential for formate generation. ${ }^{26,27}$ In addition, very few electrocatalysts perform $\mathrm{CO}_{2}$ reduction to acetate due to the low activity of $\mathrm{C}-\mathrm{C}$ coupling. ${ }^{28}$ Therefore, it is urgent to develop new catalysts for the transformation of $\mathrm{CO}_{2}$ to formate and acetate. Copper-based $\mathrm{CO}_{2} \mathrm{RR}$ catalysts are well-known for their capability of producing $\mathrm{C}_{2}^{+}$products, but they suffer from low selectivity and product diversity. ${ }^{29,30}$ Recent Cu-based catalysts have demonstrated great potential for the production of formate and acetate, ${ }^{28,29}$ however, with lower faradaic efficiency (FE).

Metal-organic frameworks (MOFs) with high porosity and designable metal clusters and organic linkers arouse significant research interest in biomedical, energy and environmental applications, such as drug delivery, enzyme inhibition, separation and catalysis. ${ }^{31-34}$ The atomic-level periodicity of metal complexes or metal clusters in MOFs allows the precise control over the rational design of the active metals as potential electrocatalysts for the $\mathrm{CO}_{2} \mathrm{RR} \cdot{ }^{\mathbf{1 5 , 1 9 , 3 5 - 3 8}}$ The successful application of most bulk MOFs as electrocatalysts is largely hindered by their poor electrical conductivity and inevitable gas diffusion barrier, ${ }^{39}$ which could be significantly improved by adjusting the synthetic method to form nano-MOFs, especially twodimensional (2-D) MOF nanosheets. ${ }^{\mathbf{4 0 , 4 1}}$ Nevertheless, to the best of our knowledge, 2-D MOF nanosheets have not yet been explored in the $\mathrm{CO}_{2}$ electroreduction.

It is now well accepted that an electrocatalyst undergoes in situ structural transformation under reaction conditions, which 
has been largely underestimated. ${ }^{42,43}$ 2-D MOF nanosheets under cathodization conditions have not been studied before. Thus, we choose copper(II)-5,10,15,20-tetrakis(4-carboxyphenyl) porphyrin-Cu(II) ( $\mathrm{Cu}_{2}$ (CuTCPP)) nanosheets with two different copper chemical environments as a potential $\mathrm{CO}_{2}$ electrocatalyst. One is the porphyrinic $\mathrm{Cu}$, which has been shown as an electrocatalyst for the formation of $\mathrm{CH}_{4} \cdot{ }^{44}$ The other is the $\mathrm{Cu}$ paddle wheel, the cluster in the famous HKUST-1, which is efficient in $\mathrm{CH}_{4}$ and $\mathrm{C}_{2} \mathrm{H}_{4}$ production. ${ }^{4,45}$

Here, we report the efficient and selective electroreduction of $\mathrm{CO}_{2}$ to formate and acetate by a 2-D Cu-MOF nanosheet catalyst. The FE for the formation of two liquid products reached up to $85.2 \%$ with a total current density of $4.5 \mathrm{~mA} \mathrm{~cm}^{-2}$. The turnover frequency (TOF) of the catalyst for formate and acetate formation could reach as high as $2037 \mathrm{~h}^{-1}$ and $148 \mathrm{~h}^{-1}$, respectively. This high efficiency is significantly different from that of common $\mathrm{Cu}$ catalysts, such as $\mathrm{Cu}_{2} \mathrm{O}, \mathrm{CuO}, \mathrm{Cu}$ and a porphyrin- $\mathrm{Cu}$ (II) complex (CuTCPP). Ex situ powder X-ray diffraction (XRD), scanning electron microscopy (SEM), X-ray photoelectron spectroscopy (XPS), transmission electron microscopy (TEM) and Fourier transform infrared spectroscopy (FT-IR) confirmed the cathodized reconstruction of 2-D MOF nanosheets to the heterostructures of $\mathrm{CuO}$, $\mathrm{Cu}_{2} \mathrm{O}$ and $\mathrm{Cu}_{4} \mathrm{O}_{3}$ through the $\mathrm{Cu}(\mathrm{HCOO})_{2}$ and $\mathrm{Cu}(\mathrm{OH})_{2}$ intermediates. Meanwhile, the CuTCPP complex was still anchored on the catalyst and could enhance the activity of the catalyst. This result reveals the fundamental significance of cathodized restructuring for highly selective production of formate and acetate on pre-designed MOF electrocatalysts.

\section{Results and discussion}

\section{Preparation and characterization of $\mathrm{Cu}_{2}(\mathrm{CuTCPP})$ nanosheets}

$\mathrm{Cu}_{2}$ (CuTCPP) has a porous 2D layered reticular framework structure with $\mathrm{Cu}$ porphyrin ligands connected through $\mathrm{Cu}_{2}(\mathrm{COO})_{4}$ paddle wheels (Scheme $1 \mathrm{a}$ and Fig. S1†). The adjacent layers stack in parallel, generating vertical $1 \mathrm{D}$ channels along the $c$ axis. The XRD pattern of the as-prepared product was consistent with that of $\mathrm{Cu}_{2}(\mathrm{CuTCPP})$ (Fig. 1a). ${ }^{\mathbf{4 6 , 4 7}}$ The broad peaks in the XRD pattern were due to the nanosheet feature. After dispersion in ethanol by ultrasonication, these nanosheets showed layered structures with thin thickness in the SEM image (Fig. 1c). The TEM image revealed that the $\mathrm{Cu}_{2}(\mathrm{CuTCPP})$ nanosheets had a smooth surface, and uniform and ultrathin thickness with high aspect ratio, which resulted in the partial curling of nanosheet edges (Fig. 1d). Atomic force microscopy (AFM) measurements showed that the nanosheets had a homogeneous thickness of $\sim 3.7 \mathrm{~nm}$, indicating only 8 layers (Fig. $1 \mathrm{~b}$ and $\mathrm{S} 1 \dagger$ ). Notably, the direct synthesis of few-molecularlayer MOF nanosheets on a large scale is rarely reported, ${ }^{\mathbf{4 6 , 4 7}}$ although this type of flat and high-aspect-ratio nanosheet is very desirable for electrocatalysis because of its advantages over bulk materials in regard to reducing the diffusion kinetics barrier and enhancing the electron transfer.

\section{Electrochemical $\mathrm{CO}_{2}$ reduction by $\mathrm{Cu}_{2}(\mathrm{CuTCPP})$ nanosheets}

The electrocatalytic $\mathrm{CO}_{2} \mathrm{RR}$ activity of $\mathrm{Cu}_{2}(\mathrm{CuTCPP})$ nanosheets on a FTO electrode was evaluated in $\mathrm{CH}_{3} \mathrm{CN}$ solution with $1 \mathrm{M}$ $\mathrm{H}_{2} \mathrm{O}$ and $0.5 \mathrm{M}$ ionic liquid 1-ethyl-3-methylimidazolium tetrafluoroborate $\left(\mathrm{EMIMBF}_{4}\right)$ in a two-compartment electrochemical H-type cell (Scheme 1b). ${ }^{3}$ The organic electrolyte with water and ionic liquid components was chosen to control proton concentration and enhance $\mathrm{CO}_{2}$ solubility, respectively. ${ }^{48-50}$ The linear sweep voltammetry (LSV) curves of $\mathrm{Cu}_{2}(\mathrm{CuTCPP})$ in $\mathrm{N}_{2}$ saturated and $\mathrm{CO}_{2}$-saturated electrolytes showed different cathodic waves from $0.5 \mathrm{~V}$ to $-2.0 \mathrm{~V}$ versus $\mathrm{Ag} / \mathrm{Ag}^{+}$(Fig. $\mathrm{S} 2 \dagger$ ). In the $\mathrm{CO}_{2}$-saturated electrolyte, a steep increase of current density in the negative sweep started from $-1.2 \mathrm{~V}$ versus $\mathrm{Ag} / \mathrm{Ag}^{+}$indicating significant $\mathrm{CO}_{2}$ reduction (Fig. $\mathrm{S} 2 \dagger$ ). Meanwhile, a blank experiment with a FTO electrode was also performed since FTO a)

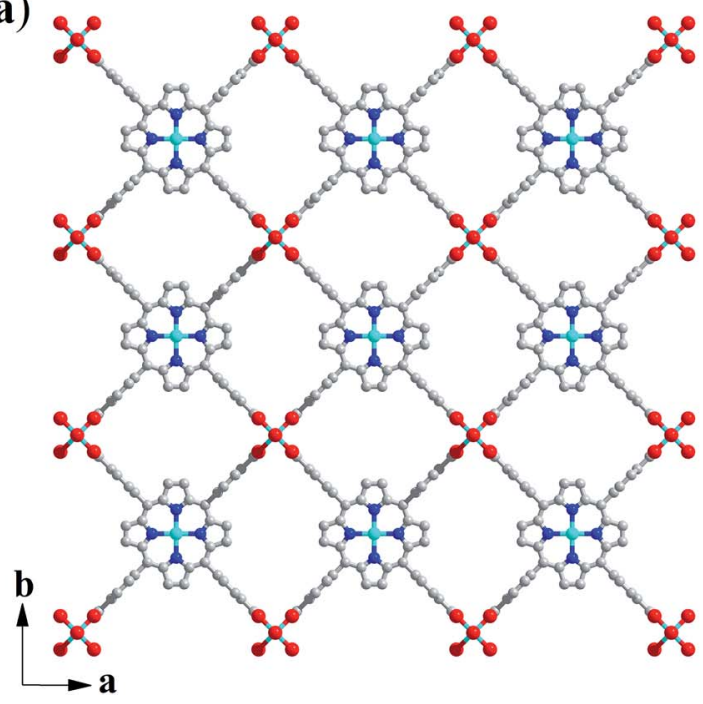

b)

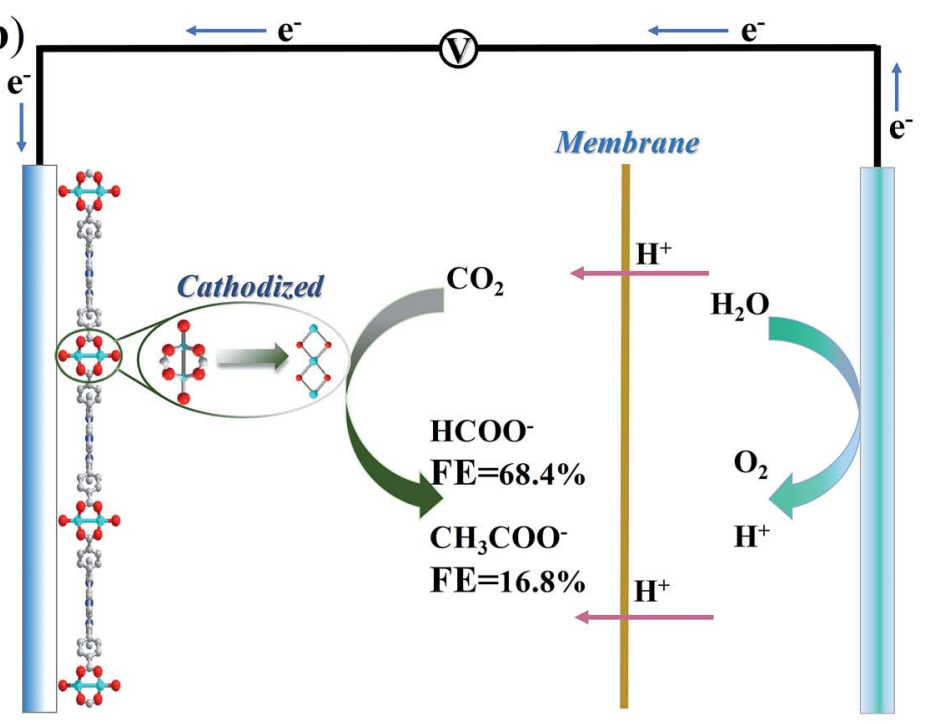

Scheme 1 (a) Crystal structure of $\mathrm{Cu}_{2}$ (CuTCPP) nanosheets along the $c$ axis. Red is $\mathrm{O}$, blue is N, grey is $\mathrm{C}$ and cyan is $\mathrm{Cu}_{\text {; }}(\mathrm{b}) \mathrm{CO}_{2}$ electrochemical reduction system with $\mathrm{Cu}_{2}$ (CUTCPP) nanosheets as the catalyst. 
a)

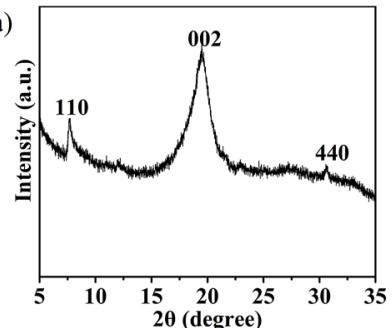

c)

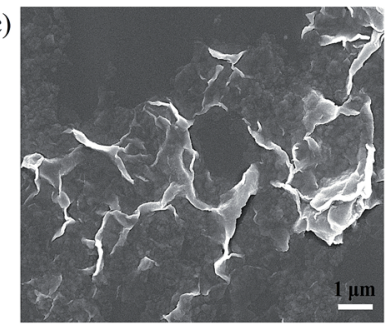

Fig. 1 (a) XRD pattern of $\mathrm{Cu}_{2}$ (CuTCPP) nanosheets; (b) AFM image of the nanosheets, inset: the thickness curve; (c) SEM image of $\mathrm{Cu}_{2}(-$ CUTCPP) nanosheets; (d) TEM image of $\mathrm{Cu}_{2}$ (CUTCPP) nanosheets.

is F-doped $\mathrm{SnO}_{2}$, which is also the active material for the $\mathrm{CO}_{2} \mathrm{RR}$ (Fig. S3 $\dagger)$. We found that only a small amount of CO $(\mathrm{FE}<10 \%)$ was produced as the reduction product, ruling out the possible formate generation from the FTO substrate.

In order to identify and quantify the reduction products, electrolysis was performed at different potentials between $-1.40 \mathrm{~V}$ and $-1.65 \mathrm{~V}$ versus $\mathrm{Ag} / \mathrm{Ag}^{+}$for $5 \mathrm{~h}$. Resultant gaseous products were periodically sampled and examined using gas chromatography (GC), while the liquid products were analyzed after electrolysis by nuclear magnetic resonance (NMR) spectroscopy. We found that formate and acetate were the two dominant reduction products, accompanied by a small amount of $\mathrm{CO}$ and $\mathrm{CH}_{4}$ from the $\mathrm{CO}_{2} \mathrm{RR}$ as well as $\mathrm{H}_{2}$ from the HER. The FEs for the formation of different products at various potentials were calculated and are shown in Fig. 2a. Formate and acetate were reliably and reproducibly detected at as positive as $-1.40 \mathrm{~V}$ versus $\mathrm{Ag} / \mathrm{Ag}^{+}$. Initially, the faradaic efficiencies were $28.1 \%$ and $11.6 \%$, respectively, which then quickly rose to $61.5 \%$ and $12.3 \%$ at $-1.55 \mathrm{~V}$ versus $\mathrm{Ag} / \mathrm{Ag}^{+}$. The faradaic efficiency for the formation of the two gaseous products, $\mathrm{CO}$ and $\mathrm{CH}_{4}$, remained small $(<5 \%)$ in this range of potentials. Moreover, $\mathrm{H}_{2}$ production from the competing HER was well controlled from $-1.50 \mathrm{~V}$ to $-1.65 \mathrm{~V}$.

However, the catalyst delivered a significant decrease of cathodic current density during the first $1 \mathrm{~h}$ and then a stable cathodic current density of $4.5 \mathrm{~mA} \mathrm{~cm}^{-2}$ (Fig. 2b). The first $1 \mathrm{~h}$ changes of current density indicated possible chemical restructuring of the catalyst under the cathodization conditions. It is also worth noting that the decrease from a total FE of $100 \%$ at $-1.60 \mathrm{~V}$ and $-1.65 \mathrm{~V}$ might indicate the hidden consumption of electrons by the side reactions as well (Fig. 2a). The initial increase in $i-t$ curves and the insufficient total $\mathrm{FE}$ values both indicated the possible redox-based chemical restructuring of the $\mathrm{Cu}_{2}(\mathrm{CuTCPP})$ catalyst. Thus, the production of formate and acetate as a function of electrolysis time was
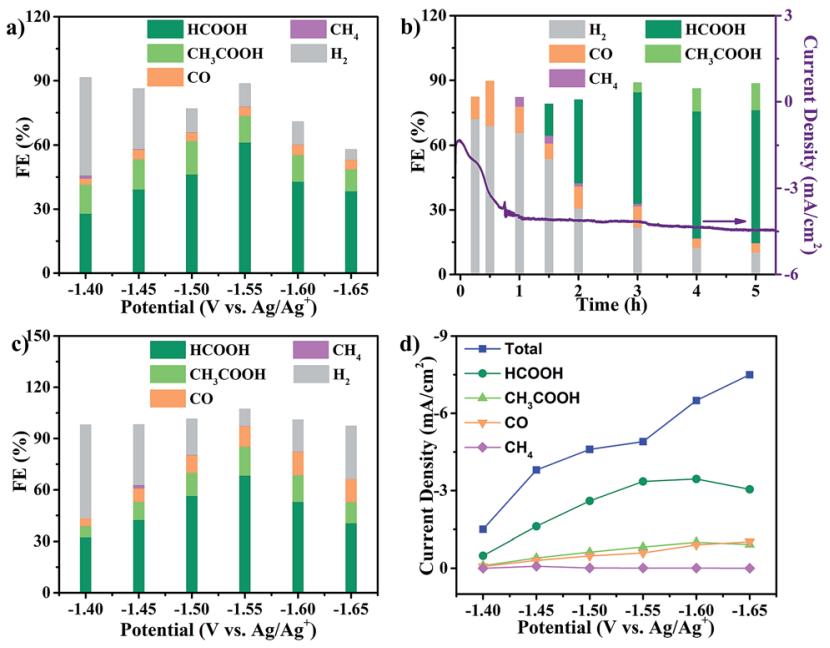

Fig. $2 \mathrm{CO}_{2} \mathrm{RR}$ performance in $\mathrm{CO}_{2}$-saturated $\mathrm{CH}_{3} \mathrm{CN}$ solution with 1 $\mathrm{M} \mathrm{H}_{2} \mathrm{O}$ and $0.5 \mathrm{M} \mathrm{EMIMBF}_{4}$. (a) Faradaic efficiencies of $\mathrm{Cu}_{2}$ (CuTCPP) nanosheets; (b) faradaic efficiencies of $\mathrm{Cu}_{2}$ (CuTCPP) nanosheets at different times; (c) faradaic efficiencies of pre-electrolyzed $\mathrm{Cu}_{2}(-$ CUTCPP) nanosheets; and (d) total and partial current densities for $\mathrm{CO}_{2} \mathrm{RR}$ products on pre-electrolyzed $\mathrm{Cu}_{2}$ (CUTCPP).

investigated at $-1.55 \mathrm{~V}$ (Fig. 2b). In the first $1 \mathrm{~h}$, the HER became the dominant cathodic process with a small amount of $\mathrm{CO}$ and $\mathrm{CH}_{4}$. Then, after $90 \mathrm{~min}$, formate appeared, while $\mathrm{H}_{2}$ from the HER decreased. After $3 \mathrm{~h}$, acetate appeared. After that, stable production of formate and acetate occurred.

To eliminate the side reactions during the initial process and further confirm the activity of the final cathodized catalyst, $\mathrm{Cu}_{2}$ (CuTCPP) nanosheets were pre-electrolyzed at $-1.55 \mathrm{~V}$. Then, the $\mathrm{CO}_{2} \mathrm{RR}$ was performed with fresh electrolyte at various potentials (Fig. 2c). The highest faradaic efficiencies for formate and acetate formation were increased to $68.4 \%$ and $16.8 \%$ at $-1.55 \mathrm{~V}$ versus $\mathrm{Ag} / \mathrm{Ag}^{+}$, respectively, with a total faradaic efficiency of $85.2 \%$. Furthermore, the partial current densities for $\mathrm{CO}_{2} \mathrm{RR}$ products on the $\mathrm{Cu}_{2}(\mathrm{CuTCPP})$ catalyst were calculated and plotted against the working potentials (Fig. 2d). The maximum values of $j_{\text {formate }}$ and $j_{\text {acetate }}$ are $3.5 \mathrm{~mA} \mathrm{~cm} \mathrm{~cm}^{-2}$ and $1.0 \mathrm{~mA} \mathrm{~cm}{ }^{-2}$, respectively, at $-1.60 \mathrm{~V}$ versus $\mathrm{Ag} / \mathrm{Ag}^{+}$. What's more, at $-1.55 \mathrm{~V}$ versus $\mathrm{Ag} / \mathrm{Ag}^{+}$, with a maximum total faradaic efficiency of $85.2 \%$ and a surface active site density of $3.16 \times$ $10^{-8} \mathrm{~mol} \mathrm{~cm}^{-2}$ (Fig. S4 $\dagger$ ), the TOF of the catalyst for formate and acetate production could reach as high as $2037 \mathrm{~h}^{-1}$ and $148 \mathrm{~h}^{-1}$, respectively (Fig. S5 $\dagger$ ), which outperformed that of most of the reported catalysts. ${ }^{\mathbf{5 1 , 5 2}}$

To confirm the carbon source of the $\mathrm{CO}_{2} \mathrm{RR}$ process, a control experiment under a $\mathrm{N}_{2}$ atmosphere was performed (Fig. S6 $\dagger$ ). $\mathrm{H}_{2}$ was the only product, which demonstrated that formate and acetate were produced from the reduction of $\mathrm{CO}_{2}$, but not from the organic part or the impurities in the electrolyte or MOF material. The continual production of formate and acetate as shown by the kinetic data also supports that the carbon source was $\mathrm{CO}_{2}$. Water concentration was also an important factor and was optimized since the competitive HER also uses $\mathrm{H}_{2} \mathrm{O}$ as the proton source (Fig. S7 $\dagger$ ). Without $\mathrm{H}_{2} \mathrm{O}$, no 
products could be detected, for both the HER and $\mathrm{CO}_{2} \mathrm{RR}$. The $\mathrm{CO}_{2} \mathrm{RR}$ is significant because of the unusually low FE for the HER at a water concentration of $1.0 \mathrm{M}$, indicating that $\mathrm{H}_{2} \mathrm{O}$ is not only the proton source but also important in the cathodization procedure to generate an effective catalyst (Fig. S8†). Since CO is a possible intermediate, ${ }^{53}$ we explored the direct CO reduction. However, only the HER occurred with $\mathrm{Cu}_{2}(\mathrm{CuTCPP})$ as the catalyst for the electrocatalytic $\mathrm{CO}$ reduction (Fig. S9†).

\section{Comparison with other $\mathrm{Cu}$ catalysts}

The restructuring of a $\mathrm{Cu}$ catalyst to other active $\mathrm{Cu}$-containing species is not rare in electrocatalyst research. ${ }^{42}$ Before the elucidation of structural changes of the $\mathrm{Cu}_{2}(\mathrm{CuTCPP})$ catalyst, we first surveyed the $\mathrm{CO}_{2} \mathrm{RR}$ activity of $\mathrm{Cu}, \mathrm{CuTCPP}, \mathrm{Cu}_{2} \mathrm{O}$, and $\mathrm{CuO}$, which are common $\mathrm{Cu}$ catalysts (Fig. 3 and S10†). The catalysts were confirmed by XRD (Fig. S11-S14†) and were evaluated as $\mathrm{CO}_{2}$ electrocatalysts under identical conditions compared to those of $\mathrm{Cu}_{2}(\mathrm{CuTCPP})$ nanosheets.

Control experiments with $\mathrm{Cu}, \mathrm{CuTCPP}, \mathrm{CuO}$, and $\mathrm{Cu}_{2} \mathrm{O}$ suggested that although in the presence of $\mathrm{CO}_{2}$, the HER became the dominant cathodic process for all four catalysts, accompanied by the co-generation of a small amount of $\mathrm{CO}, \mathrm{CH}_{4}, \mathrm{HCOOH}$ and $\mathrm{CH}_{3} \mathrm{COOH}$. The FE and yield of products at different potentials were calculated and are shown in Fig. 3 and Table S1, $\uparrow$ respectively. Negligible $\mathrm{CO}_{2} \mathrm{RR}$ was observed on the $\mathrm{Cu}$ catalyst with mainly $\mathrm{CO}$ and $\mathrm{CH}_{4}$ as products $(\mathrm{FE}<5 \%)$ while no formate and acetate were observed. The CuTCPP complex was chosen as the counterpart since it is one of two $\mathrm{Cu}$ components in $\mathrm{Cu}_{2}(-$ CuTCPP). However, although CO was produced with a FE of $20 \%$ at potentials from $-1.50 \mathrm{~V}$ to $-1.65 \mathrm{~V}, \mathrm{H}_{2}$ from the HER was still the major product. $\mathrm{CuO}$ and $\mathrm{Cu}_{2} \mathrm{O}$ were two common forms of copper oxides for the $\mathrm{CO}_{2} \mathrm{RR}^{54}$ In our results, $\mathrm{CuO}$ was significant to generate both $\mathrm{HCOOH}$ (an $\mathrm{FE}$ of $14.7 \%$ at $-1.5 \mathrm{~V}$ ) and $\mathrm{CH}_{3}$ $\mathrm{COOH}$ (an $\mathrm{FE}$ of $5.8 \%$ at $-1.45 \mathrm{~V}$ ), while only $\mathrm{HCOOH}$ was
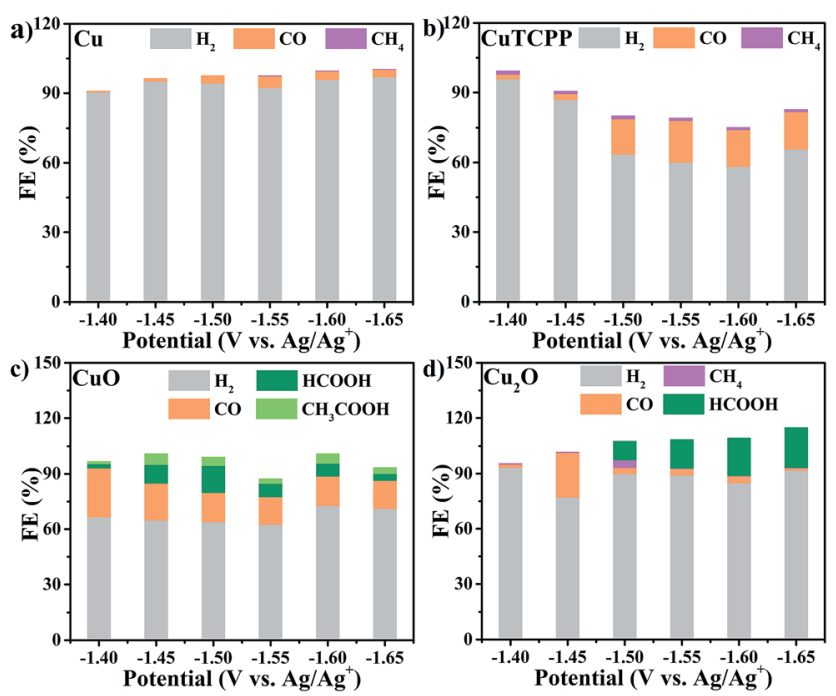

Fig. 3 Faradaic efficiencies for formation of different products in the $\mathrm{CO}_{2} \mathrm{RR}$ with different catalysts: (a) $\mathrm{Cu}$, (b) CuTCPP, (c) $\mathrm{CuO}$, and (d) $\mathrm{Cu}_{2} \mathrm{O}$. obtained with $\mathrm{Cu}_{2} \mathrm{O}$ with an $\mathrm{FE}$ up to $21.5 \%$ (Table $\mathrm{S} 1 \dagger$ ). The above results indicated that the production of formate and acetate on $\mathrm{Cu}_{2}(\mathrm{CuTCPP})$ was superior to that on the four individual $\mathrm{Cu}$ counterparts. Thus, no single component was possibly responsible for the high activity and selectivity of formate and acetate production, while the functionalities of the porphyrin ligand and copper paddle wheel clusters should be reconsidered.

\section{Cathodized reconstruction of $\mathrm{Cu}_{2}(\mathrm{CuTCPP})$ nanosheets}

The high selectivity and activity towards formate and acetate production with the reductive formation from $\mathrm{Cu}_{2}(\mathrm{CuTCPP})$ encouraged us to pursue the "real catalyst". These structural changes were explored with ex situ XRD, SEM, TEM, XPS and FTIR characterization.

The potential $\mathrm{Cu}$ species from the $\mathrm{Cu}(\mathrm{II})$ paddle-wheel nodes during cathodized reconstruction were first revealed at $-1.55 \mathrm{~V}$ with different reaction times (Fig. 4a and S15†). After the optimal electrocatalysis at $-1.55 \mathrm{~V}$ for $15 \mathrm{~min}$, the XRD peak of the $\mathrm{Cu}_{2}(\mathrm{CuTCPP})$ catalyst on FTO electrodes shifted from $20.39^{\circ}$ to a lower value of $20.04^{\circ}$ with the appearance of three new peaks $\left(\mathrm{Cu}(\mathrm{HCOO})_{2}\right.$ at $13.40^{\circ}$, an unassigned peak at $21.37^{\circ}$, and $\mathrm{Cu}(\mathrm{OH})_{2}$ at $\left.23.42^{\circ}\right)$. At $15 \mathrm{~min}$, the morphology changed from well-shaped nanosheets to partially amorphous layered structures (Fig. S16a and S16b $\dagger$ ). Then, after $30 \mathrm{~min}$, two XRD peaks disappeared $\left(21.37^{\circ}\right.$ and $\left.23.42^{\circ}\right)$, and the peak intensity of $\mathrm{Cu}(\mathrm{HCOO})_{2}$ at $13.40^{\circ}$ increased, while three new peaks $\left(\mathrm{Cu}(\mathrm{HCOO})_{2}\right.$ at $26.55^{\circ}, 40.68^{\circ}$ and $\left.53.74^{\circ}\right)$ appeared. At $30 \mathrm{~min}$, the morphology changed from partially amorphous layered structures to amorphous solid (Fig. S16c $\dagger$ ). Next, after $60 \mathrm{~min}$, other XRD peaks of $\mathrm{Cu}(\mathrm{HCOO})_{2}$ disappeared with only one peak at $13.40^{\circ}$ remaining, while two peaks at $21.37^{\circ}$ and $23.42^{\circ}$ were observed again. At the same time, new dendritic structures appeared (Fig. S16d $\dagger$ ). Finally, after $90 \mathrm{~min}$, the XRD showed multiple peaks of $\mathrm{CuO}, \mathrm{Cu}_{2} \mathrm{O}$ and $\mathrm{Cu}_{4} \mathrm{O}_{3}$, while the amorphous morphology was observed again (Fig. S16e $\dagger$ ). These resultant products could be the real active catalysts in regard to the $\mathrm{CO}_{2} \mathrm{RR}$ results at the same time interval (Fig. 2b).

Meanwhile, we also performed ex situ XRD and SEM characterization at different voltages (Fig. S17 and S18†). Similar intermediate species, $\mathrm{Cu}(\mathrm{HCOO})_{2}$, and morphology changes were observed with the same confirmed final catalysts $\mathrm{CuO}$, $\mathrm{Cu}_{2} \mathrm{O}$ and $\mathrm{Cu}_{4} \mathrm{O}_{3}$. These continual changes in XRD patterns and SEM pictures at different reaction times and working potentials showed that the $\mathrm{Cu}_{2}(\mathrm{CuTCPP})$ catalyst had changed to $\mathrm{CuO}$, $\mathrm{Cu}_{2} \mathrm{O}$ and $\mathrm{Cu}_{4} \mathrm{O}_{3}$ with confirmed intermediates $\mathrm{Cu}(\mathrm{HCOO})_{2}$ and $\mathrm{Cu}(\mathrm{OH})_{2}$. It is worth noting that the above ex situ XRD and SEM monitored cathodization process was fully consistent with the first $1 \mathrm{~h}$ current density fluctuation in electrolysis and the $\mathrm{CO}_{2} \mathrm{RR}$ time course experiment, further confirming the reliability of ex situ characterization techniques in our system.

To further elucidate the final catalyst and active sites of cathodized $\mathrm{Cu}_{2}(\mathrm{CuTCPP})$ nanosheets, TEM and XPS were utilized. HRTEM images with $d=0.230 \mathrm{~nm}$ for $\mathrm{Cu}_{2} \mathrm{O}$ (111) and $d=0.257 \mathrm{~nm}$ for $\mathrm{CuO}(111), \mathrm{Cu}_{2} \mathrm{O}(-111)$ and/or $\mathrm{Cu}_{4} \mathrm{O}_{3}(211)$ were obtained from ex situ cathodized catalysts with a longer electrolysis time of $5 \mathrm{~h}$. Furthermore, the $\mathrm{Cu}_{2}(\mathrm{CuTCPP})$ 
a)

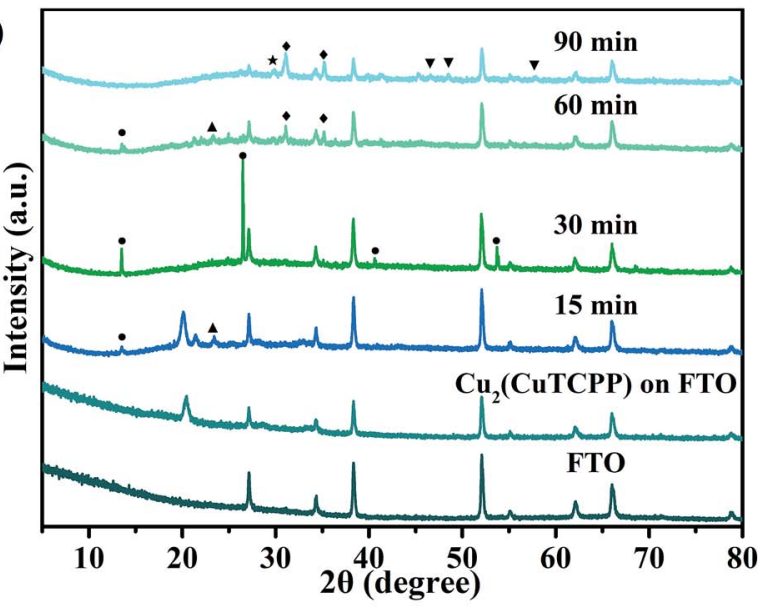

b)

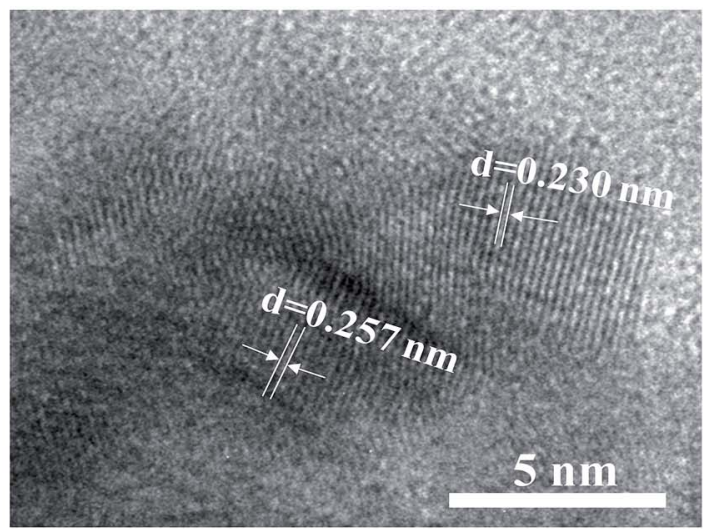

c)

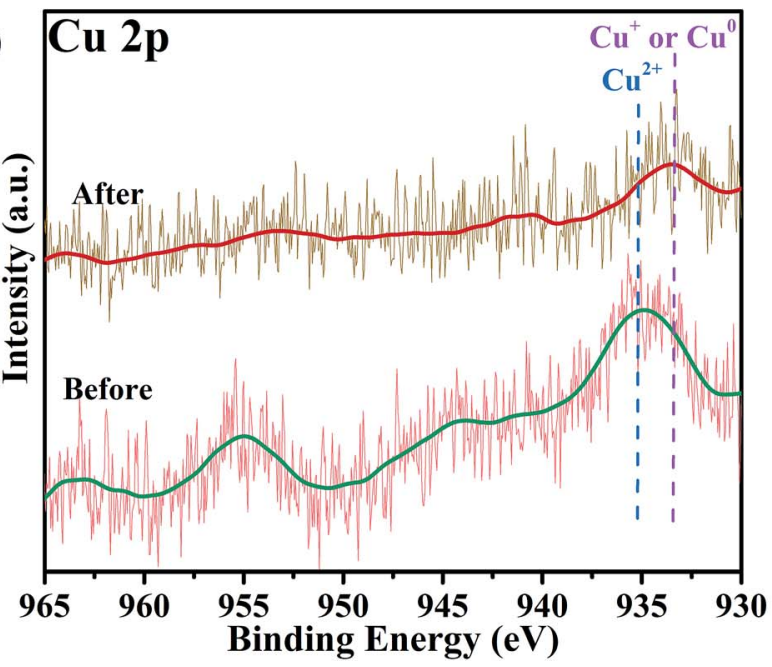

d)

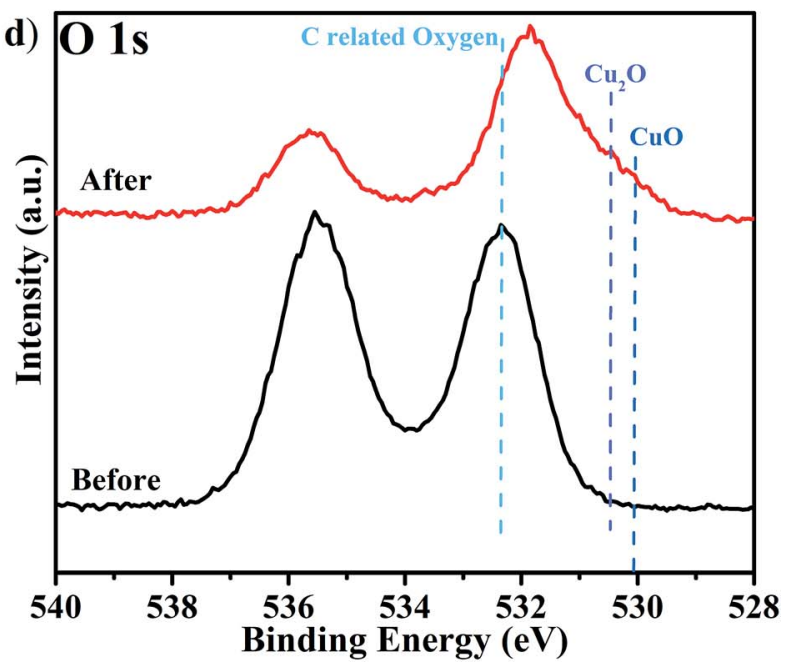

Fig. 4 (a) XRD of $\mathrm{Cu}_{2}$ (CuTCPP) nanosheets on a FTO electrode with different reaction times $\left(\boldsymbol{C u}(\mathrm{HCOO})_{2} ; \bullet \mathrm{Cu}_{4} \mathrm{O}_{3} ; \boldsymbol{\Delta} \mathrm{Cu}(\mathrm{OH})_{2} ; \boldsymbol{\nabla} \mathrm{CuO} ; \star\right.$ $\mathrm{Cu}_{2} \mathrm{O}$ ); (b) HRTEM after $5 \mathrm{~h}$ reaction; (c) Cu 2p XPS spectra and (d) O $1 \mathrm{~s}$ XPS spectra of $\mathrm{Cu}_{2}(\mathrm{CuTCPP})$ on FTO before and after $5 \mathrm{~h}$ reaction. All potentials were set at $-1.55 \mathrm{~V}$ vs. $\mathrm{Ag} / \mathrm{Ag}^{+}$.

nanosheets and cathodized $\mathrm{Cu}_{2}(\mathrm{CuTCPP})$ on FTO electrodes before and after the $\mathrm{CO}_{2} \mathrm{RR}$ were characterized by XPS (Fig. $4 \mathrm{c}$ and d). The spectra of $\mathrm{Cu} 2 \mathrm{p}$ clearly showed that the as-prepared $\mathrm{Cu}_{2}$ (CuTCPP) surface has $\mathrm{Cu}^{2+}$ states which are distinct from their lower binding energy states, the $\mathrm{Cu}^{+}$or $\mathrm{Cu}^{0}$, after $5 \mathrm{~h}$ electrocatalysis. Although the binding energies of the $\mathrm{Cu}^{+}$and $\mathrm{Cu}^{0}$ states were very close in the XPS spectra, Auger spectra could possibly distinguish these two states with overlapped peaks at $569.5 \mathrm{eV}$ and $572.5 \mathrm{eV}$, which were ascribed to the kinetic energy of $\mathrm{Cu}^{+}$and $\mathrm{Cu}^{2+}$, respectively. ${ }^{55}$ Only $\mathrm{Cu}^{+}$was observed, ruling out the possible existence of metallic copper (Fig. S19†). Meanwhile, XPS O1s spectra also showed that the asprepared $\mathrm{Cu}_{2}(\mathrm{CuTCPP})$ surface has $\mathrm{C}$ related oxygen, which was distinctively reduced to the lower binding energy $\mathrm{O}$ states associated with $\mathrm{Cu}_{2} \mathrm{O}$ and $\mathrm{CuO}$ after $5 \mathrm{~h}$ reaction (Fig. $4 \mathrm{~d}$ ). ${ }^{42}$ Additional peaks in $\mathrm{O}$ 1s spectra were related to chemisorbed oxygen in carboxylic groups or water. ${ }^{56,57}$

The strong intensity of $\mathrm{O}$ 1s XPS peaks indicated the existence of O-containing species. Thus, it is crucial to elucidate the status and possible functionality of the TCPP ligand. First, from the pictures of the electrolyte before and after electrocatalysis, we could exclude the possibility that the porphyrin ligand dissolved in the electrolyte after reaction (Fig. S20†). The NMR spectra further showed no TCPP peaks for the electrolyte samples (Fig. S21†). Second, the peak at $1650 \mathrm{~cm}^{-1}$ in the FT-IR spectrum confirmed that the ligand was still anchored to the surface of the catalyst during the reaction (Fig. S22 $\dagger$ ). ${ }^{46,47,58}$ Third, a control experiment in which a physical mixture of $\mathrm{CuO}$ and CuTCPP with a molar ratio of $2: 1$ was tested as a catalyst for the $\mathrm{CO}_{2}$ RR (Fig. S23广) showed that $\mathrm{CuO} / \mathrm{CuTCPP}$ was significant to generate both $\mathrm{HCOOH}(\mathrm{FE}$ of $31.1 \%$ at $-1.55 \mathrm{~V})$ and $\mathrm{CH}_{3} \mathrm{COOH}$ ( $\mathrm{FE}$ of $17.3 \%$ at $-1.55 \mathrm{~V}$ ), the FEs being higher than that of individual $\mathrm{CuO}$ and CuTCPP (Fig. 3). It is worth noting that our cathodized catalyst was possibly anchored by TCPP through chemical bonds, in which the activity was even better than that of the physical mixture of $\mathrm{CuO} / \mathrm{CuTCPP}$. Thus, the inorganic species of the cathodized $\mathrm{Cu}_{2}(\mathrm{CuTCPP})$ nanosheets were confirmed as $\mathrm{CuO}, \mathrm{Cu}_{2} \mathrm{O}$ and $\mathrm{Cu}_{4} \mathrm{O}_{3}$, while the 
anchored CuTCPP could synergistically enhance the activity of the final catalyst and result in different selectivities compared to traditional $\mathrm{Cu}$ catalysts as well as $\mathrm{Cu}-\mathrm{MOFs}$ such as HKUST- $1 .{ }^{45}$

\section{Conclusions}

This research discovered the high selectivity and efficiency in electrocatalytic $\mathrm{CO}_{2}$ reduction to formate and acetate with cathodized copper porphyrin MOF nanosheets. The comparison with $\mathrm{CuO}, \mathrm{Cu}_{2} \mathrm{O}, \mathrm{Cu}$ and CuTCPP counterparts and XRD, XPS, FT-IR and HRTEM studies confirmed the cathodized reconstruction to a mixture of $\mathrm{CuO}, \mathrm{Cu}_{2} \mathrm{O}$ and $\mathrm{Cu}_{4} \mathrm{O}_{3}$ anchored with the TCPP ligand. Although inevitable structural changes occurred in the cathodization process, this predesigned feature of 2-D MOF nanosheets will bring precise control over the preparation of electrocatalysts.

\section{Conflicts of interest}

There are no conflicts to declare.

\section{Acknowledgements}

This work is financially supported by the NSFC (No. 21505076), the Young Elite Scholar Support (YESS) Program from CAST, the Program of Jiangsu Specially-Appointed Professor, the NSF of Jiangsu Province of China (No. BK20150967), the Innovation Team Program of Jiangsu Province of China, and the Priority Academic Program Development of Jiangsu Higher Education Institutions.

\section{Notes and references}

1 H. Takeda, K. Ohashi, A. Sekine and O. Ishitani, J. Am. Chem. Soc., 2016, 138, 4354-4357.

2 J. Bonin, M. Robert and M. Routier, J. Am. Chem. Soc., 2014, 136, 16768-16771.

3 S. Zhang, P. Kang, M. Bakir, A. M. Lapides, C. J. Dares and T. J. Meyer, Proc. Natl. Acad. Sci. U. S. A., 2015, 112, 1580915814.

4 U. Kang, S. K. Choi, D. J. Ham, S. M. Ji, W. Choi, D. S. Han, A. Abdel-Wahab and H. Park, Energy Environ. Sci., 2015, 8, 2638-2643.

5 X. Yang, E. A. Fugate, Y. Mueanngern and L. R. Baker, ACS Catal., 2017, 7, 177-180.

6 F. Li, L. Chen, M. Xue, T. Williams, Y. Zhang, D. R. MacFarlane and J. Zhang, Nano Energy, 2017, 31, 270277.

7 S. Huo, Z. Weng, Z. Wu, Y. Zhong, Y. Wu, J. Fang and H. Wang, ACS Appl. Mater. Interfaces, 2017, 9, 28519-28526.

8 Y. Wu, J. Jiang, Z. Weng, M. Wang, D. L. J. Broere, Y. Zhong, G. W. Brudvig, Z. Feng and H. Wang, ACS Cent. Sci., 2017, 3, 847-852.

9 Z. Sun, T. Ma, H. Tao, Q. Fan and B. Han, Chem, 2017, 3, 560587.

10 Y. Huang, A. D. Handoko, P. Hirunsit and B. S. Yeo, ACS Catal., 2017, 7, 1749-1756.
11 W. Zhang, Q. Qin, L. Dai, R. Qin, X. Zhao, X. Chen, D. Ou, J. Chen, T. T. Chuong and B. Wu, Angew. Chem., Int. Ed., 2018, 57, 9475-9479.

12 Y. Liu, Y. Zhang, K. Cheng, X. Quan, X. Fan, Y. Su, S. Chen, H. Zhao, Y. Zhang and H. Yu, Angew. Chem., Int. Ed., 2017, 129, 15813-15817.

13 S. Verma, B. Kim, H.-R. M. Jhong, S. Ma and P. J. A. Kenis, ChemSusChem, 2016, 9, 1972-1979.

14 H. Tao, X. Sun, S. Back, Z. Han, Q. Zhu, A. W. Robertson, T. Ma, Q. Fan, B. Han, Y. Jung and Z. Sun, Chem. Sci., 2018, 9, 483-487.

15 I. Hod, M. D. Sampson, P. Deria, C. P. Kubiak, O. K. Farha and J. T. Hupp, ACS Catal., 2015, 5, 6302-6309.

16 N. Han, Y. Wang, L. Ma, J. Wen, J. Li, H. Zheng, K. Nie, X. Wang, F. Zhao, Y. Li, J. Fan, J. Zhong, T. Wu, D. J. Miller, J. Lu, S.-T. Lee and Y. Li, Chem, 2017, 3, 652-664.

17 X. Zhang, Z. Wu, X. Zhang, L. Li, Y. Li, H. Xu, X. Li, X. Yu, Z. Zhang, Y. Liang and H. Wang, Nat. Commun., 2017, 8, 14675.

18 C. Costentin, S. Drouet, M. Robert and J.-M. Savéant, Science, 2012, 338, 90-94.

19 N. Kornienko, Y. Zhao, C. S. Kley, C. Zhu, D. Kim, S. Lin, C. J. Chang, O. M. Yaghi and P. Yang, J. Am. Chem. Soc., 2015, 137, 14129-14135.

20 C. Zhao, X. Dai, T. Yao, W. Chen, X. Wang, J. Wang, J. Yang, S. Wei, Y. Wu and Y. Li, J. Am. Chem. Soc., 2017, 139, 80788081.

21 Y. Liu, S. Chen, X. Quan and H. Yu, J. Am. Chem. Soc., 2015, 137, 11631-11636.

22 Y. Deng, Y. Huang, D. Ren, A. D. Handoko, Z. W. Seh, P. Hirunsit and B. S. Yeo, ACS Appl. Mater. Interfaces, 2018, 10, 28572-28581.

23 F. Li, L. Chen, G. P. Knowles, D. R. MacFarlane and J. Zhang, Angew. Chem., Int. Ed., 2017, 56, 505-509.

24 Y. Zhang, L. Chen, F. Li, C. D. Easton, J. Li, A. M. Bond and J. Zhang, ACS Catal., 2017, 7, 4846-4853.

25 J. Gu, F. Héroguel, J. Luterbacher and X. Hu, Angew. Chem., Int. Ed., 2018, 130, 2993-2997.

26 X. Sun, Q. Zhu, X. Kang, H. Liu, Q. Qian, Z. Zhang and B. Han, Angew. Chem., Int. Ed., 2016, 55, 6771-6775.

27 N. Han, Y. Wang, H. Yang, J. Deng, J. Wu, Y. Li and Y. Li, Nat. Commun., 2018, 9, 1320.

28 Y. Wang, D. Wang, C. J. Dares, S. L. Marquard, M. V. Sheridan and T. J. Meyer, Proc. Natl. Acad. Sci. U. S. A., 2017, 201713962.

29 K. P. Kuhl, E. R. Cave, D. N. Abram and T. F. Jaramillo, Energy Environ. Sci., 2012, 5, 7050-7059.

30 C. W. Li and M. W. Kanan, J. Am. Chem. Soc., 2012, 134, 7231-7234.

31 M. Xu, S. Yuan, X.-Y. Chen, Y.-J. Chang, G. Day, Z.-Y. Gu and H.-C. Zhou, J. Am. Chem. Soc., 2017, 139, 8312-8319.

32 T. Rodenas, I. Luz, G. Prieto, B. Seoane, H. Miro, A. Corma, F. Kapteijn, F. X. Llabrés i Xamena and J. Gascon, Nat. Mater., 2014, 14, 48.

33 L. Zhu, X.-Q. Liu, H.-L. Jiang and L.-B. Sun, Chem. Rev., 2017, 117, 8129-8176. 
34 H. Zheng, Y. Zhang, L. Liu, W. Wan, P. Guo, A. M. Nyström and X. Zou, J. Am. Chem. Soc., 2016, 138, 962-968.

35 R. S. Kumar, S. S. Kumar and M. A. Kulandainathan, Electrochem. Commun., 2012, 25, 70-73.

36 J. Albo, D. Vallejo, G. Beobide, O. Castillo, P. Castaño and A. Irabien, ChemSusChem, 2017, 10, 1100-1109.

37 R. Hinogami, S. Yotsuhashi, M. Deguchi, Y. Zenitani, H. Hashiba and Y. Yamada, ECS Electrochem. Lett., 2012, 1, H17-H19.

38 L. Ye, J. Liu, Y. Gao, C. Gong, M. Addicoat, T. Heine, C. Wöll and L. Sun, J. Mater. Chem. A, 2016, 4, 15320-15326.

39 W. H. Li, K. Ding, H. R. Tian, M. S. Yao, B. Nath, W. H. Deng, Y. Wang and G. Xu, Adv. Funct. Mater., 2017, 27, 1702067.

40 Y. Wang, P. Hou, Z. Wang and P. Kang, ChemPhysChem, 2017, 18, 3142-3147.

41 S. Zhao, Y. Wang, J. Dong, C.-T. He, H. Yin, P. An, K. Zhao, X. Zhang, C. Gao and L. Zhang, Nat. Energy, 2016, 1, 16184. 42 S. Y. Lee, H. Jung, N.-K. Kim, H.-S. Oh, B. K. Min and Y. J. Hwang, J. Am. Chem. Soc., 2018, 140, 8681-8689.

43 P. Grosse, D. Gao, F. Scholten, I. Sinev, H. Mistry and B. Roldan Cuenya, Angew. Chem., Int. Ed., 2018, 130, 63006305.

44 Z. Weng, Y. Wu, M. Wang, J. Jiang, K. Yang, S. Huo, X.-F. Wang, Q. Ma, G. W. Brudvig, V. S. Batista, Y. Liang, Z. Feng and H. Wang, Nat. Commun., 2018, 9, 415.

45 D.-H. Nam, O. S. Bushuyev, J. Li, P. De Luna, A. Seifitokaldani, C.-T. Dinh, F. P. García de Arquer, Y. Wang, Z. Liang, A. H. Proppe, C. S. Tan, P. Todorović, O. Shekhah, C. M. Gabardo, J. W. Jo, J. Choi, M.-J. Choi, S.-W. Baek, J. Kim, D. Sinton, S. O. Kelley, M. Eddaoudi and E. H. Sargent, J. Am. Chem. Soc., 2018, 140, 11378-11386.
46 G. Xu, K. Otsubo, T. Yamada, S. Sakaida and H. Kitagawa, J. Am. Chem. Soc., 2013, 135, 7438-7441.

47 G. Xu, T. Yamada, K. Otsubo, S. Sakaida and H. Kitagawa, J. Am. Chem. Soc., 2012, 134, 16524-16527.

48 Q. Zhu, J. Ma, X. Kang, X. Sun, H. Liu, J. Hu, Z. Liu and B. Han, Angew. Chem., Int. Ed., 2016, 128, 9158-9162.

49 B. A. Rosen, A. Salehi-Khojin, M. R. Thorson, W. Zhu, D. T. Whipple, P. J. Kenis and R. I. Masel, Science, 2011, 1209786.

50 X. Sun, X. Kang, Q. Zhu, J. Ma, G. Yang, Z. Liu and B. Han, Chem. Sci., 2016, 7, 2883-2887.

51 T. N. Huan, P. Simon, A. Benayad, L. Guetaz, V. Artero and M. Fontecave, Chem.-Eur. J., 2016, 22, 14029-14035.

52 T. N. Huan, E. S. Andreiadis, J. Heidkamp, P. Simon, E. Derat, S. Cobo, G. Royal, A. Bergmann, P. Strasser and H. Dau, J. Mater. Chem. A, 2015, 3, 3901-3907.

53 K. J. P. Schouten, Y. Kwon, C. J. M. van der Ham, Z. Qin and M. T. M. Koper, Chem. Sci., 2011, 2, 1902-1909.

54 H. Mistry, A. S. Varela, C. S. Bonifacio, I. Zegkinoglou, I. Sinev, Y.-W. Choi, K. Kisslinger, E. A. Stach, J. C. Yang, P. Strasser and B. R. Cuenya, Nat. Commun., 2016, 7, 12123. 55 F. Deng, N. Li, S. Tang, C. Liu, H. Yue and B. Liang, Chem. Eng. J., 2018, 334, 1943-1953.

56 L.-Z. Fan, S. Qiao, W. Song, M. Wu, X. He and X. Qu, Electrochim. Acta, 2013, 105, 299-304.

57 L.-Z. Fan, J.-L. Liu, R. Ud-Din, X. Yan and X. Qu, Carbon, 2012, 50, 3724-3730.

58 W. Tu, J. Lei, P. Wang and H. Ju, Chem.-Eur. J., 2011, 17, 9440-9447. 